\title{
2020 Teaching \& Learning Conference Track Summaries
}

$\mathrm{T}$ rack summaries of the nine tracks at the 2020 Teaching and Learning Conference, which took place February 7-9 in Albuquerque, NM, are published in the following pages. These summaries include highlights and themes that emerged from the research presented in each track. The summary authors also issued recommendations for faculty, departments, and the discipline as a whole-providing suggestions for new strategies, resources, and approaches aimed at advancing political science education throughout the discipline and beyond.

The presentations discussed below are available on APSA Preprints.

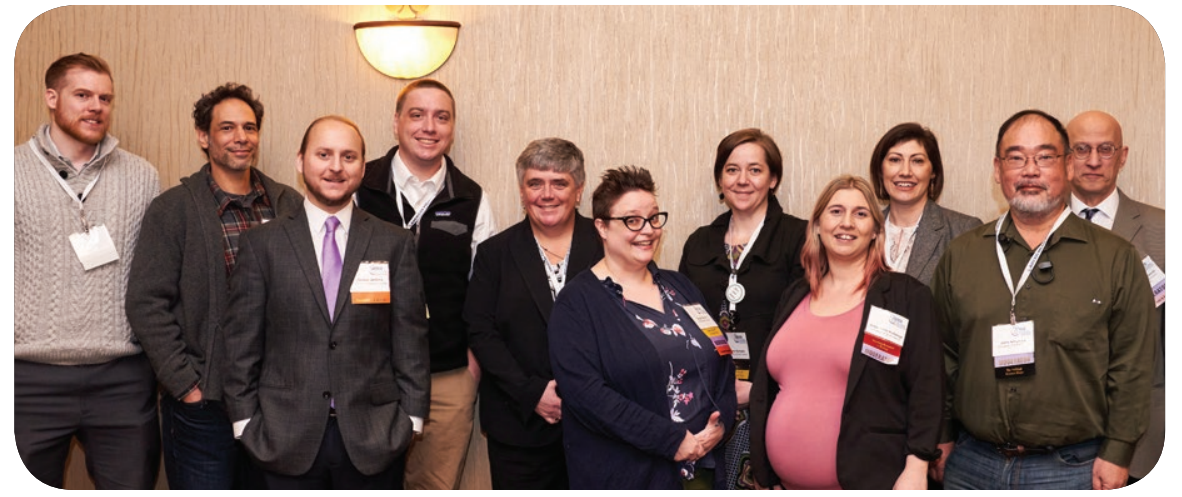

Above: Track moderators and program committee co-chairs gather at the APSA Teaching \& Learning Conference in Albuquerque, NM. From left to right: John Phillips (Austin Peay University), Anthony Kammas (University of Southern California), Clinton Jenkins (Birmingham-Southern College), Tom Ringenberg (Rockhurst University), Mary McHugh (Merrimack College), Bobbi Gentry (Bridgewater College), Shane Nordyke (University of South Dakota), Julia Marin Hellwege (University of South Dakota), Sara Parker (Chabot College), John Ishiyama (University of North Texas), Khalil “Haji” Dokhanchi (University of Wisconsin, Superior)

\section{Civic Engagement}

\author{
Christopher Hallenbrook, California State University, Dominguez Hills \\ Brian Hanson, Wayne State College \\ Alexander Jorgensen, Winona State University \\ Sondra Richards, Midland College
}

$\mathrm{T}$ his year's Civic Engagement track included participants and papers that engaged several broad themes: engaging our students through dialogue; creating active learning exercises to increase student civic engagement; challenges in assessing civic engagement projects; the role of political scientists in developing engaged and informed citizens; and building a culture of civic engagement on our campuses and in our communities. While we agreed that the field of political science has an essential role in teaching civic engagement and civic skills to shore up American democracy, there was also a realization that the challenges for meeting this goal are both varied and substantial.

\section{DEVELOPING CIVIC SKILLS THROUGH DIALOGUE AND ACTIVE LEARNING}

One theme of the civic engagement track was dialogue, its importance to education inside and outside of the classroom, and its role as an essential feature of political engagement. Unsurprisingly, this began with a discussion of Socratic pedagogy. We emphasized that the critical thinking developed through Socratic dialogue involves more than just taking existing ideas apart; it is also essential that students develop the next step of synthesizing new ideas about the world. By developing both steps of this process in the classroom, we help students equip themselves with the most fundamental tools of civic engagement, the ability to challenge the world as it exists and envision it as it ought to be.

The invitation of controversial, or divisive, campus speakers presents an opportunity in which these dialogue skills are needed to navigate civic life. Two track participants studied in detail the considerations used by students in determining whether to promote campus dialogue or shut down speakers on campus. They found a variety of considerations and varying levels of willingness to engage, but conclude students are more willing to engage in uncomfortable dialogues than some media reports might lead one to believe.

Another method for creating dialogue and civic engagement is through the use of active learning in the political science classroom. The use of active learning creates tension in teaching due to the tradeoff between covering content and the impact of experiential learning. However, active learning facilitates student "buy in" because it allows students to slow down, reflect, take time and engage with the material. Using the ideas set forth by J.S. Mill, Ramona Grey suggests the idea that "less is more"-or in Mill's words, "The world reads too much, and too quickly, to read well"creates a path forward for de-politicized civic engagement because it allows shared questioning and deeper understanding. Building on these ideas, track participants were skeptical of "teaching by mentioning," and instead emphasized the importance of personal attachment developed through creating meaning, developing understanding, and active learning. In other words, instructors should consider teaching fewer topics, teaching topics we care about, and teaching slower.

Active learning in the political science classroom can indirectly or directly address civic engagement. First, active learning can 
indirectly address the development of civic skills by focusing on practice with particular concepts within the curriculum in order to facilitate understanding and increase student engagement. The focus on developing deeper understanding of key concepts through the use of active learning indirectly contributes to civic engagement by linking political knowledge to critical thinking. Several examples of this type of active learning were presented in the civic engagement track.

Recognizing that her students were struggling with the concept of party systems, Kerri Ryer created a "cookie party" simulation to demonstrate the ways in which voting rules impact election outcomes. Jeffrey Bernstein and Cameron Armstrong use "think alouds" to help students navigate difficult political dialogues, thereby identifying bottlenecks in understanding and roadblocks for civic engagement. Emily Kathryn Lynch uses debates in large lecture classes to allow students to practice engaging in difficult political discussions. Her use of debates is grounded in the political communication and political psychology literature suggesting the development of political knowledge and critical thinking skills contribute to civic engagement. Diana M. Owen presents similar research but suggests that even as we address gaps in political knowledge, we need to be aware of inequities in the development of civil skills and civic empowerment.

Similarly, Alex Jorgensen and Kara Lindaman use active learning techniques to directly address civic skills and civic engagement. Using resources from the National Issues Forum, Jorgensen and Lindaman use the "wicked problems" format to engage students in solving unstructured, relentless problems that may not be solved in traditional institutional settings through the use of deliberative dialogue. This format gives students the opportunity to practice using their voices in solving real problems currently facing our society. Early findings show success in developing student confidence in the political arena, although the results are not evenly distributed across gender and race. Additionally, there is a role for active learning in creating opportunities for classrooms to engage the campus and community in areas such as voter registration, get out the vote drives, and political education. However, this type of active learning (or service learning) requires a commitment from the institution and community in partnership with the classroom experience.

Focusing on the challenges of teaching students in China, Yitsui Tseng similarly highlights the potential weakness of failing to identify challenges unique to particular cultures when encouraging the development of civic skills. With an awareness of the challenges across different cultures and the diverse needs of students, active learning techniques, such as debates, still have the potential to decrease the civic empowerment gap across cultures, and between more and less privileged students. By returning to the idea of personal attachment, allowing students to develop their own personal narrative as part of the development of political knowledge and civic skills, the gap in civic empowerment across diverse student populations may be mitigated.

Active learning strategies can facilitate civic engagement even in the online course environment. Online education presents unique challenges to developing dialogue. How do we create dialogue between students, and between students and their communities, without the physical meeting space of a classroom? One paper took up this challenge, seeking to promote dialogue and civic engagement in online classes through creation of public-facing websites. Kristoffer Rees and Chera LaForge use an assignment that creates a "sense of place" for students through designing a website for a public monument near them, and each student developing a website discussing their hometown, in which they had to promote a civic improvement project. The presenting professor reported that many students proposed their improvements to their municipal governments. This type of "sense of place" assignment builds social capital by having students engage with citizens and/or community leaders.

The active learning model rests on the belief that students do not need more information, they need more ability to analyze and understand information. Within the active learning model the role of the instructor shifts from teacher to coach. Professional development is critical to the process, as it is important to be thoughtful about the shift to active learning and the coaching model. Active learning should be grounded in developing meaning and understanding. In all attempts to use active learning, instructors should consciously create spaces that decrease inequity among students.

Active learning techniques are chal- lenging to implement, not just because they require a shift in approach and decisions about course content, but the time invested in the active learning model is rarely supported or recognized by institutions for the purposes of promotion and tenure. Future instructors also rarely receive much training in active learning during their graduate education. Additionally, it is important that instructors are thoughtful about the use of active learning, because active learning that is not grounded in meaning, understanding, and equity is problematic.

\section{ASSESSING CIVIC ENGAGEMENT PROJECTS}

Assessing civic engagement projects introduces challenges not found in assessment of traditional learning projects. The wide variety of projects presented in our track relied on various measures of learning outcomes. Jorgensen and Lindaman used a pre-andpost survey format through Qualtrics to measure participant outcomes in their project. Similarly, Owens employed a pretestposttest design in measuring students' acquisition of civic knowledge from participating in the James Madison Legacy Project. Lynch used TopHat to collect student responses to questions posed before and after in-class debates in her large introductory classes. Surveys may be most suitable for civic engagement projects that include many participants. However, several projects presented in our track utilized different methodology.

But assessments should not always be the main focus because they worsen time constraints that limit active learning and classroom dialogue. Christopher Gaelan Murphy argued we should use the art of dialectic as a teaching and learning tool to engage students. This is what we already do at the university. How much effort should we put into assessing the Socratic method through any formal methodology? Administrators' emphasis on assessment does not necessarily advance the development of our students as citizens.

\section{CALL TO ACTION}

The Civic Engagement track explored many different topics and methods of increasing student civic engagement. From our discussions it is clear that such projects are time consuming. The tension is often between covering material, or spending significant time developing, preparing, and executing these projects. The time constraint is detri- 
mental, especially without proper support from administrators. Most faculty cannot justify committing to these types of projects if they are not given credit towards tenure and promotion.

Civic engagement has been added to new Higher Learning Commission criteria, effective in September 2020, for determining whether an institution of higher education merits accreditation, or reaffirmation of accreditation. The new standards state, "The institution provides opportunities for civic engagement, in a diverse, multicultural society and globallyconnected world," and "encourages curricular or cocurricular activities that prepare students for informed citizenship." Further, the new criteria require that institutions' "processes demonstrate inclusive and equitable treatment of diverse populations" and "foster a climate of respect among all student, faculty, and administrators from a range of diverse backgrounds, ideas, and perspectives." Our institutions of higher learning are being tasked with not only giving students the knowledge they need to be informed citizens, but also building their civic skills and teaching the norms of engagements for a diverse and inclusive democracy. Who better to guide our institutions' efforts to achieve these objectives than political scientists?

However, efforts by faculty to increase civic engagement on campus and in the community are often not supported by administrators. Civic engagement activities are not generally included in the criteria for promotion and tenure, and faculty engaged in teaching and research do not have the time or available resources to engage in projects to develop the civic culture of their campus. We should encourage administrators, in order to align with the new accreditation, to devote resources to building civic engagement and civic learning in and out of the classroom. Students may only take a few courses in the general education requirements that seek to develop them as citizens. Institutions should include credit towards promotion and tenure for faculty who create opportunities for students to develop into more informed and engaged citizens, and provide financial support for leading class and campus groups in service learning projects and community engagement activities.

We are tasked with developing the civic skills of students who bring with them a broad range of dispositions and backgrounds. This includes finding new methods of presenting what is most important for students' understanding of their role as citizens by facilitating dialogue and introducing active learning exercises that aid them in thinking beyond their own experiences, both in and out of the classroom. Our role in this effort is a form of public service. We are teaching for the health of our democracy, and developing citizens requires institutional support and recognition of efforts in service of this task.

Therefore, we call on APSA to issue a statement of support for these efforts that encourages administrations to recognize faculty work in developing informed citizens and creating a culture of civic engagement on campuses, and in communities, in the form of credit towards promotion and tenure, as it is in the interest of the institution to align with new Higher Learning Commission criteria for accreditation.

\section{Community Engagement and Experiential Learning}

\author{
Clinton M. Jenkins, Birmingham-Southern College \\ Carl Cilke, Northeastern University \\ Bobbi Gentry, Bridgewater College
}

citizenship communicates course content and also pushes students to think conceptually about their communities and what makes them a citizen. In addition, this also prepares students to make political decisions and be a part of a community of learning. Further evidence of political science's benefits to thinking about communities was Sun's presentation of results from a series of quasi-experiments which demonstrate that we may be able to teach social capital-the bedrock of a community's successful governance-to members of various communities, as well as in the classroom. Sun uses an empirical method to test three different techniques-motivational, analytical, and practical-and presents evidence for the effectiveness of these interventions at increasing social capital across both the US and China.

Communities can expand learning as students experience cultures different from their own. Analyzing political science study abroad courses, Jennifer Ostojski and Carl Cilke presented a novel understanding about how students' experiences during study abroad trips vary significantly based upon the sponsoring faculty member's approach. They show that how much structure faculty impose on the study abroad experience-both in terms of the structuring of time abroad and in the assignments, such as reflections-affects the scope and type of experiences students have.

\section{INTERNSHIPS}

Internships are an increasingly common form of experiential learning for undergraduates and may benefit both providers and students. Using evaluations of intern performance by on-site intern supervisors, Shannon McQueen, Clinton Jenkins, and 
Susan L. Wiley find that on-site internship supervisors generally report satisfaction with interns' work. However, a substantial portion of these supervisors expressed a desire for interns to exhibit more initiative, improve on their writing and communication skills, and to pay more attention to detail. The authors suggest these findings help us think more carefully about the sorts of skills educators and university internship supervisors should encourage students to develop as they prepare for internships. Arthur H. Auerbach finds that across three internship programs of varying resources, academic requirements, focus, and size, students reported generally high levels of satisfaction with their internship. Students also reported that their internships had a significant impact on them, with large portions of survey respondents indicating they gained new skills and knowledge, improved their ability to work with others, were able to apply skills they learned in the classroom, and gained a better sense of their strengths and weaknesses.

Concerns of equity and accessibility of internships still exist, particularly the difficulties posed by unpaid internships. Additionally, it is important that internships are more than simply employment training, and instead have an academic component integrated with them. The duty of institutions is to ensure the protection of students completing internships. One issue discussed for further research was looking at the long-term effects of these internship opportunities, and evaluating their benefits beyond simply the period during which a degree is completed.

\section{STATE AND LOCAL}

Jeff Dense presented a model for engaging students in their community with a project that asks students to identify an issue facing the local community and to address it with a policy proposal. This proposal would be taken to state or local political leaders in an effort to get the proposal adopted. Kelly Clancy presented a model pairing project-based learning with service learning. Students work with a community partner during the semester and are also asked to complete a project-or projects-throughout the semester related to the course topic and their work with the community organization.

Dense posits this model offers many benefits, notably the chance for students to apply material from their courses to completing the project. It additionally provides students opportunities to develop and practice skills critical to entering the workforce and increases students' engagement with their local communities. Clancy identifies similar benefits, and also suggests these benefits can be reinforced by integrating community, project-based learning across an entire curriculum, from first year seminars to senior capstone courses.

Dense and Clancy highlight numerous challenges. Dense focused on the lack of buy-in from state or local officials and the slow speed at which the policy and political processes move, among others. Clancy demonstrates the substantial role of institutional buy-in and support in efforts to establish and continue project-based service learning with community partners. This may suggest a challenge for faculty at institutions without such buy-in or resources to aid in the effort.

Larger questions include how to integrate project-based learning without significant institutional support, concerns with access and equity stemming from students working for community partners without compensation and the need for students to physically get to those partners, and the challenges of integrating project-based learning into online education. Some suggested solutions to overcoming a lack of institutional support were to look for corporate donors and to start with smaller projects first, which often require less institutional buy-in or resources. Others suggested increasing accessibility for students that may have difficulty getting off campus by inviting community partners to campus.

\section{INTERNATIONAL}

Noting the many benefits to studying abroad, Jennifer Wallace focused on the substantial number of students who don't participate in those opportunities for a variety of reasons, including perceived or real institutional barriers. These barriers include credits taken abroad not transferring or credit equivalency issues for fulfilling degree or major requirements, issues with financial aid transferring to cover time abroad, and lack of faculty or department support for or recognition of study abroad experiences, among others. These barriers influence the behavior of political science students. This leads students to choose not to study abroad or to pick shorter term study abroad trips, and to a less diverse pool of students opting to study abroad in any form. Wallace suggests solutions including political science departments more intentionally integrate study abroad experiences into the major curriculum and revisiting financial aid policies to allow financial aid to transfer to study abroad experiences, among others.

Jonathan Snow further highlighted the benefits of study abroad experiences through analysis of his experience taking students abroad to Israel and the West Bank. Snow reports that by the end of their trip students exhibited a significantly more nuanced understanding of the Arab-Israeli conflict, as well as the extent of coexistence between the two cultures, than did students taking a traditional course on the subject. He documented a variety of study abroad pedagogical practices to achieve these outcomes. These included front-loading academic content before the trip, thus ensuring all students had a baseline understanding prior to going abroad, perceiving his role as a facilitator for students to gain experiences rather than as the interpreter of their experiences, and whenever possible providing access to multiple narratives on historical events, with the aim of providing relative balance in perspectives.

Finally, Patrick McNamara continued highlighting the benefits of studying abroad and international study, presenting on the Young Southeast Asian Leaders Initiative, where young people from the Association of Southeast Asian Nations travel to the US to develop their civic engagement and leadership skills through a series of courses and other experiences. In this program, the young leaders are brought to the US and, through civic engagement, develop an action plan to fix injustice in their home countries. A higher goal of this program is to create a transformational experience for both these young leaders and the contacts they meet in the US. McNamara notes that the experience benefits American students at the host institutions, the students studying abroad in the US as part of the program, and the educators, by pushing all parties to view their experiences, and assumptions about society, civic engagement, and leadership in a new, broader context.

Integrating experiential learning and community engagement in different contexts poses a challenge, but we should embrace the variety of opportunities for students in the US and abroad. While concerns of a perceived trade-off exists between political science course content and engaging in experiential learning, the reality is that it's not the case-experien- 
tial learning and study abroad opportunities often reinforce the content gained from coursework, they don't come at the expense of that content.

\section{COMMUNITY PARTNERSHIPS}

Clare M. Daniel presented a model for creating a service-learning internship experience, offering students paid internships with community partners engaged in providing reproductive health services or promoting reproductive rights. The program develops students' career readiness while providing the opportunity to engage in meaningful service learning and improves the institution's relationship with the community, as well as creating a community among participants. The program is entirely donor funded through fundraising efforts, which covers the pay for student interns. Jennifer Noe Pahre partners with members of the local justice community as co-teachers of an introductory undergraduate course on the law. During bi-weekly field trips, students attend legal proceedings and meet with various actors in the justice system, such as judges, attorneys of various types, and others.

Both papers demonstrated the advantages of working with community partners. Daniel demonstrates that developing relationships with a related set of community partners for students to intern at, as well as with community funders, can yield a program that permits students to have meaningful experiences with commu- nity organizations, while also overcoming some of the challenges presented by unpaid internships. Pahre documents that working with community partners to provide students direct experiences with the subject matter yields higher levels of student engagement with, and understanding of, material that is often viewed as boring and difficult to grasp in traditional classroom settings. Additionally, Pahre reports high levels of buy-in and continued support from the community partners, suggesting community members are open to a variety of partnership types.

Discussion highlighted that evident in both presentations was the importance of group cohesion among participants-such as cohesion gained from sharing experiences-to enhancing the impact of the learning experience. The discussion also expressed concerns with equity and accessibility of internship and service-learning opportunities, including preventing interns from exploitation by partner organizations. In addition, the promises of donorfunded experiences to increase access was discussed, as were the potential downfalls if funders have political or other motives that may go against the broader goals of the program.

\section{CONCLUSION}

One major theme was the challenge of the availability of resources necessary for faculty to successfully offer community engagement and experiential learning opportunities. The panels demonstrated there are a variety of different pedagogical approaches to developing community and experiential learning opportunities. These approaches provide increased value to the learning process. But they require time and resources to be implemented. It is necessary that there be buy-in from both faculty and institutions. Second, appropriate recognition for faculty work in providing experiential learning opportunities when being evaluated, and for those on the tenure track, when coming up for promotion and/or tenure was a frequent concern. The time and effort involved in developing and managing experiential learning opportunities for students often comes at the cost of focusing more on other items, such as research, and often isn't counted more than a regular course. Finally, perhaps most strongly, our track called upon faculty, institutions of higher education, and the discipline to focus more on issues of equity and accessibility in the provision of opportunities for community engagement and experiential learning. Concerns were raised about the substantial financial and time commitments required of students by experiential opportunities. Other concerns raised were about ensuring access to students who may have difficulty leaving campus. As experiential learning and community engagement practices continue to become more common, exploring the ideas and themes will grow in importance.

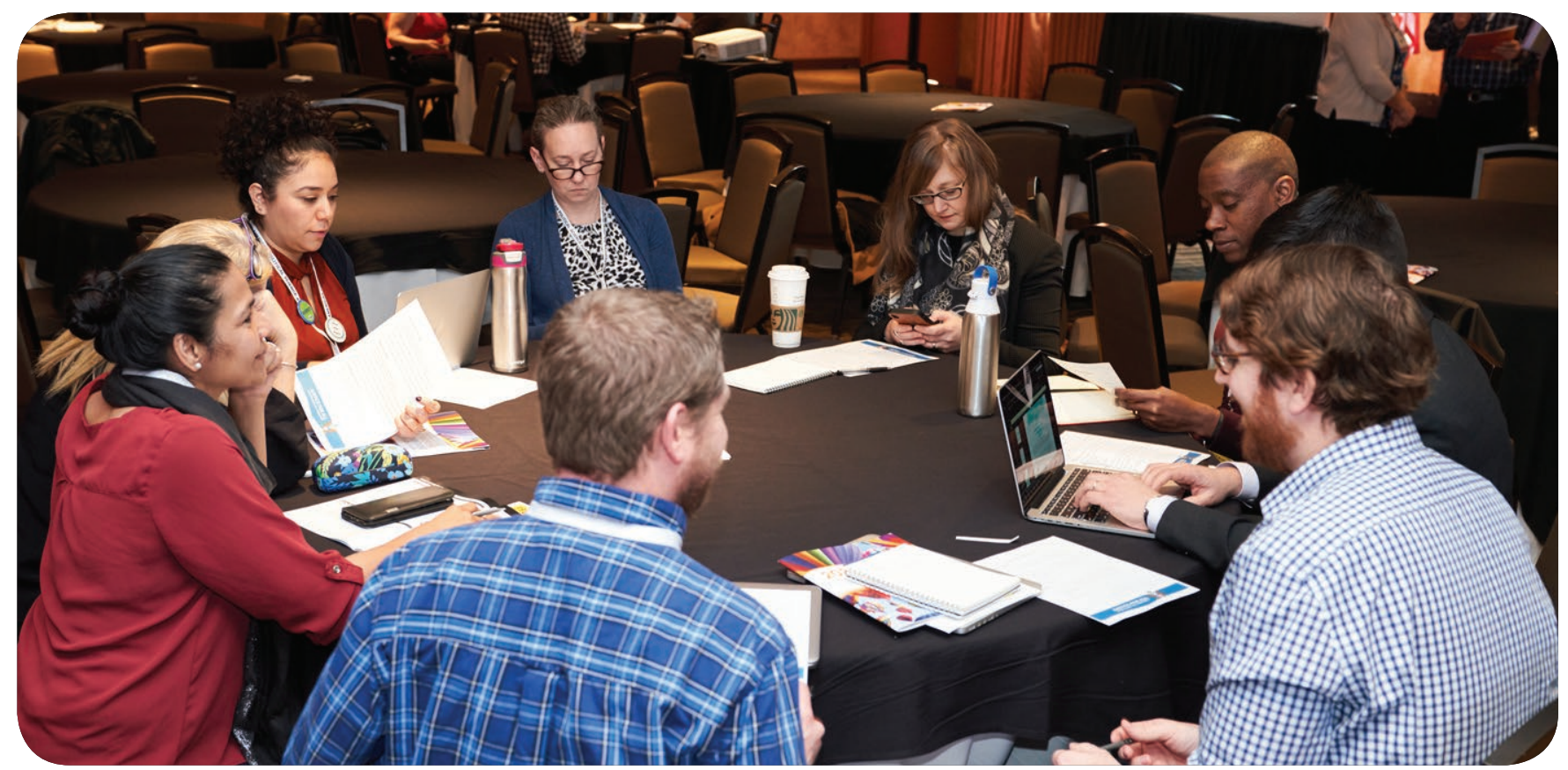




\title{
General Education and Interdisciplinary Teaching
}

\author{
Anthony Kammas, University of Southern California
}

T he General Education and Interdisciplinary Studies track featured eight papers spread over five panels. Present in each of these five panels were approximately $5-10$ energetic and insightful attendees. Panelists offered wellconstructed presentations, and the spirit of our discussions and debates was critical but quite friendly. The attendees were diverse with regard to gender, age, ethnicity, region, and academic positions. Diversity also extended to institutional type, ranging from US Research 1 universities to community colleges, including one Canadian institution. It is this aspect in particular, our diversity, that truly added significant range and depth to our shared comprehension and challenges. The challenges facing those tasked with instructing political science general education classes arguably could be expressed in a familiar refrain or two. However, we found that the solutions to these challenges reflected the multifaceted interests, expertise, and imagination of the scholars that answered the call. From innovative pedagogical strategies that mobilized the latest technological fashion to interdisciplinary approaches aimed at breaking students out of their near addictions to smart devices and social media, the panelists covered all bases. Lastly, the practicality of a general education in political matters was never lost sight of, either. The thought and practice of our civic and political existence was interwoven in all we discussed.

\section{A FAMILIAR REFRAIN (OR TWO)}

Whether it is a student with an unrelated major fulfilling a requirement or a political science major concerned with future prospects, these twin refrains ineluctably and consistently surface: "why do I need to study this?" and "what can I do with this degree?" To be caught without an answer is to seemingly negate one's validity as an educator; furthermore, given that the subject matter in question is politics, the paucity of a weighty response may equally negate the gravity of our shared civic duty. Such dilemmas were on the minds of our track participants, and their papers addressed these concerns in thoughtful and dynamic ways. Drawing from experiences in the classroom and their broader communities, our participants shared a wealth of insight aimed at addressing the oft troubling refrains arising from legitimate student concerns.

\section{Why do I need to study this?}

If only the old Periclean adage about politics being interested in you despite your lack of interest in it rang with any urgency, but alas. In an effort to reignite such a spirit, two papers proceeded down parallel but distinct paths. Doug West's “Teaching Western Political Thought through Western Literature" and Khristina Haddad's "Seeing what is Said: Teaching Machiavelli's Prince through its Images," both situated the broader human connections within the scope of political knowledge. By way of literature, public images, and text, West and Haddad balanced aesthetic interests, personal interests, and political insight in pedagogical expressions that demanded readers and viewers to acknowledge the interwovenness of their individual lives and civic existence. Their answers to "why study this?" are because as we learn something of each other, we discover new things about ourselves, and vice versa. Furthermore, the mediums chosen for the transmission of this knowledge draw in disciplines and media often considered outside the typical scope of the political. West's and Haddad's papers-which are extensions of their work as educators-illuminate how politics is everywhere, and power relationships flow through seemingly non-political discourse. Haddad's focus on 16th century public art, monuments and their inscriptions not only remind us of old forms of public discourse aimed at enlightenment, but also approximate contemporary uses of images and text. Students can compare her historical images to popular meme culture, finding connections to the past while also considering how well today's comparable discourse measures up. West's work too accomplishes the similar goal, introducing students to social worlds that may otherwise be relatively inaccessible.

The paper presented by Jarrod Kelly dealt with similar dilemmas, though his work did not focus on the substance of the material. Rather, it touched upon structure and strategies for coping with the "why" question. Kelly's work, "Level Up: Using Gamification to Improve Student Evaluation and Motivation," discussed how he melded students' interest and excitement for gaming culture with his pedagogical objectives. If students could get past the "why" dilemma through a series of gamescontests toward goals, point accumulation, and rewards, then they would be motivated to learn and do well to reap the benefits. The desired general education political science content is still being taught, and the immediate and continual gratification of points and goal acquisition is enlisted to mitigate the trepidation and frustration often felt by non-majors required to take a politics class. Despite the differences inherent in each of the papers, innovation and an interdisciplinary cross-pollination of tactics, ideas, and materials were called upon to demonstrate the worldliness and self-awareness one gains by taking such a course.

\section{What can I do with this degree?}

There were two papers that addressed this concern directly-one dealt with this matter nationally, the other had an international focus. Nicole Shoaf's "Political Science Internships: A Path to 'Workforce Ready' without Selling Out” went a long way to elucidate the benefits and challenges associated with internships. The benefits are relatively clear-students gain practical experience and can put their classroom knowledge to the test. She was quick to point out that not all internships were equal, and that there was an institutional responsibility to ensure that valuable and safe experiences were being had by the students. Shoaf also pointed out that unpaid internships were not exactly an easy sell to many first-generation college students who would benefit from paid employment outside the scope of their studies. John Barkdull's paper titled "Global Studies and Careers" raised related issues, but there was the added dimension of international travel and work. Whether the internships were 
domestic or international, matters of assessment, supervision, and evaluation were raised. Also, the dilemma of strongly encouraging internship work as opposed to requiring it was considered-in each case, the programs and institutions discussed decided on the former. The consensus in the room was clear-internships served as crucial links between the classroom and the realm of practical application. They served these ends best when well-administered by professors and staff attuned to the ways in which employers can sometimes take advantage of students in voluntary positions. Budgets, personnel, and recourses devoted to these ends was also a matter of significant concern.

\section{Why? and What?}

The track had three papers that more explicitly addressed both the "why?" and "what?" concerns. The paper by Kevin Lucas, "Internships for Credit: Linking Work Experience to Learning Objectives," was very similar to the two papers mentioned in the prior section. It differed by drawing out the more direct (if unexpected) connections between political knowledge and the workplace application of such knowledge. Lucas told the story of a student whose work in a rendering facility was so valuable that the employer invited the student to study politics and apply the knowledge as he saw fit in his duties at the plant. It turned out that the student was in fact able to meaningfully apply his classroom knowledge in a setting not traditionally considered 'political.' What the student was able to grasp was how his understanding of power, human relationships, and the various intervening factors pertaining to the regulation of people in an institutional setting was very much within the purview of traditional political science.

The final two papers under consideration, Tara Parsons' "How to use Democracy: Videos as a Tool to Engage General Education Students," and Mark Springer's "Who are You? Addressing the Identity Issue of Political Science Majors," brought together civic concerns and individual identity in ways that aimed at educating others as well as evoking students' own understanding of civic duty. With the broader demos in mind, Parsons asked her students to make "how to use democracy" videos. The two-fold effect being that students had to understand the rights, duties, and power of citizens for themselves, and then they had to instruct others through their videos. The assignments ranged from matters touching upon campus life to broader social issues such as race and poverty. Springer's paper approximated similar concerns, but proceeded by asking students who they were in society and how they understood their citizenship. Writing assignments focused on how students could change their community in practical, achievable ways. However, this strategy was coupled with pressing students to consider who was their contemporary 'Aristotle,' and how abstract thought that reached out for ideals might be woven into their practical community initiatives. During both Parsons' and Springer's presentations (which happened to be the final two of the track), many of the previously discussed notions returned and our conversations came full circle, back to the overarching theme of the track.

\section{CONCLUSION}

The study of politics must not be bound by disciplinary borders; where power is exercised it should venture. Furthermore, where there are useful means for the illumination of the exercise of power, we as educators should borrow and steal. The stakes are high-perhaps now more than ever: given the contemporary crises of political leadership amid an even worse crisis in global public heath, the study of power and politics is a matter of tremendous significance. Our students are the political agents that will care for our republic and its demos in perpetuity. It is our duty to convey the profound responsibility that accompanies being a member of the polity. If these goals are accomplished, questions of "why study this" and "what will I do with it" will no longer be asked-the answers would be bound up with a sense of identity and belonging that would require no explanation at all.

\section{The Inclusive Classroom}

\section{Adam Irish, California State University, Chico Thomas Ringenberg, Rockhurst University}

T he prior meetings of the Inclusive Classroom track of the APSA Teaching and Learning Conference (Aragon and Roy 2017; Combes, Parker, and Cravens 2016) generated freewheeling discussions of cultivating awareness, empathy, and inclusivity. Similarly, the 2020 Inclusive Classroom track covered a great deal of conceptual space both in terms of types of inclusivity examined and the levels of analysis at which this past year's studies took place.

Notably, track presenters and participants this year took a broad approach to studying and discussing classroom inclusivity. Conversations included everything from racial identity and contemporary events to international cultural engagement and inclusion of diverse textual references (e.g., ancient Greek plays, reality TV). This year's Inclusive Classroom track expanded outward from purely classroom-based understandings of inclusivity and suggested a number of new avenues for future research. Out of this year's rich diversity of studies, three specific themes emerged: access, authorizing, and action. Below, we reflect on how each of the above papers contributed to each theme.

\section{ACCESS}

How should we decide which texts, videos, and other materials are allowed into our classrooms? Furthermore, how do we promote an equality of student access to our classes? Central to any discussion of access is our choice of course materials. Megan Collins, Nathan Mitchell, and Michael Nojeim as well as William Harder offered clear and convincing arguments for open educational resources (OERs). These papers provided examples of freely available resources that reduce both the cost of college classes and, in many cases, the barriers to successful undergraduate research. As discussed by each presenter, the use of OERs requires thought engagement by instructors.

Whether accommodating the learning curve of a statistical program like $\mathrm{R}$ or sifting through OER textbooks for American 
Government, this year's presenters suggest that for OERs to be successfully adopted instructors must consider the student and educational environment. Accounting for the unique nature of teaching at an $\mathrm{HBCU}$, Collins et al. find that, compared to traditional textbooks, their adoption of OERs improved student access to readings along with student attitudes and performance in class. Harder builds on this concern for context and provides a pedagogical strategy for the use of OERs in teaching research methods. Both studies revealed the importance of reflective and critical approaches to classroom texts and tools. Harder in particular cautions that assessment will require revision where OER methodological tools are used.

Adam Hoffman and Leanne Doherty move beyond OERs to consider access of novel ideas and media. Hoffman provides a compelling review of American Government textbooks, putting numbers to the relative neglect of elite-driven explanations of American politics. This researchsupported, un-romanticized understanding of American politics may, as Hoffman argues, provide a better foundational understanding of politics as well as connect more directly to the lived experiences of students. To this end Hoffman is currently composing a textbook that takes a more elite-driven approach to understanding American government.

Doherty provides an even more direct form of access for students by analyzing the role that popular culture can play in the classroom. Specifically, Doherty focuses on youth disengagement with broader political systems. Making use of clips from contemporary sitcoms and longer popular documentaries (e.g. Shut up and Sing), she demonstrates that, despite the additional work required to acquire and stay current with popular culture, student engagement is increased through more inclusive discussions of power and decision making. As part of teaching through popular culture, Doherty turns over control to students by allowing them to bring in additional popular culture examples in the hopes of earning extra credit if the example is new to the professor.

In sum, this year's conference took a hard look at how inclusive student access affected the texts, videos, and other materials instructors choose. Whether accounting for the costs of materials or the role of power and popular culture, the papers, presenters, and discussion this year suggests that inclu- sive teaching begins long before the first student sets foot in the classroom. Echoing past concerns about digital divides, gendered structures surrounding political ambition, and trigger warnings, the selection of studies reviewed here suggest that equity of education is a function of effortful, reflective teaching which if done well can increase student engagement, achievement, and enjoyment.

\section{AUTHORIZING}

A key element to any inclusive classroom is empowering students to speak and engage, often with difficult topics concerning race, gender, power dynamics, and controversial contemporary issues. Esa Syeed's presentation this year brought home the need for blending the stories of students into the analysis of politics. Drawing from recent events like police violence in minority communities and incorporating video of minority speakers, Syeed argued for the importance of hearing these stories in the classroom as an aspect of critical pedagogy. Elaborating this point, Jamie Frueh's paper attempted a theoretical innovation centered on accepting "liberalism's bluff" that politics is rationally conducted amongst relative equals as a way of unpacking the inequality that attends politics in the tradition of Freire, hooks, and Gramsci. In Frueh's approach, special attention is paid to the educational politics of the college classroom-most directly to confronting and unsettling positions of privilege, both Frueh's and his students. From this perspective, students must feel authorized and empowered to be participants in social decisionmaking, but also in the creation and evaluation of knowledge.

Emmanuel Balogun's work extended this attention to racial politics in his presentation of a program designed to bring minority students to study abroad in Africa. While scaling such an intensive project remains an issue, Balogun's study provided a compelling example of the type of time and emotional labor required to begin to address race-in this case the broader politics linking modern black American politics and culture to African states and societies.

All the above works demonstrated the importance of authorizing student voices in the classroom. Opening space and opportunity for critical analysis of educational and societal structures is necessary, but this year's collection of presentations suggests the importance of pedagogical efforts to create classroom systems (whether based in story, questioning sessions, or travel) that authorize students to direct the questioning of structures they find themselves immersed in.

A final set of analyses presented by Mikhail Beznosov and John Pat Willerton suggest that awareness of personal psychological differences as well as involvement in a global classroom provide authorization of a different sort. Specifically, Beznosov and Willerton appealed to a cosmopolitan vision of the inclusive classroom through the incorporation of psychological testing and web-based international dialogue into the classroom. Their efforts to awaken students to psychological tendencies and cultural misperceptions stand as a further reminder that authorizing student voices is likely to require teaching interventions. In each case, Beznosov and Willerton demonstrate the usefulness of student generated content (e.g., psychological surveys, discussion comments) as a starting point for open and lively discussions about differences both real and perceived.

\section{ACTION}

Lastly, the Inclusive Classroom track this year included several studies that suggested specific actions available to cultivate greater inclusivity in the classroom. Ana Sverdlick and Pooja Rishi offered a broad review of teaching in a border town. Their report on the usefulness of active learning dovetails with much of the existing pedagogical literature but was supplemented with a compelling analysis of the structural and non-structural barriers to education in a racially and politically diverse environment. Picking up on this thread, Michelle Kim Gardiner's study put into action the Southern Poverty Law Center's "Teaching Tolerance" lesson plan. This study suggests the need to question the myriad of antiracist educational programs-specifically how and how well do they work? Gardiner's initial work suggested that there are a number of important implications of these programs that should be readily testable in the college classrooms. To the extent that inclusivity can be taught and cultivated the above studies suggest that effective programs and an awareness of obstacles will be essential for any such education.

Two more narrow studies by Danielle Hanley and Adam Irish offer specific activities to cultivate inclusivity. Hanley's evidence of the effectiveness of Greek tragedies as a pedagogical tool further supports Syeed's earlier arguments about the 
importance of narratives and storytelling. Hanley's presentation also suggested that empowering students to write their own political plays could spark both engagement and deeper thought about past and current political dynamics. Discussion about Hanley's paper revealed that inclusivity can travel across time as well as identities. Further expanding the scope of inclusivity to include geography, Irish offered a promising study of how a minimal intervention-a single video conference session between students in Chico, California and Cairo, Egypt-can dramatically reduce international biases and cultivate greater critical thinking about a complex political problem, in this study: terrorism.

All of the above papers and presentations speak to the importance of a broader understanding of inclusivity. Beyond debates over faculty diversity statements and social justice on campus, our role as educators is well served when we marry creativity with opportunity. The Inclusive Classroom track this past year provides evidence that there are many diverse ways to open our classrooms to the world and to empower our students through questions, stories, and conversations. Doing so demands intellectual energy and resources beyond our textbooks and, if this year's studies are correct, it may require a rethinking of our textbook choices. But the educational rewards of providing access, authorizing student voices, and taking inclusive actions are well worth the effort.

\section{R E F E R E N C E S}

Aragon, Janni, and Oindrila Roy. 2017. “The Inclusive Classroom." PS: Political Science \& Politics 50 (3): 4-6.

Combes, Nathan, Sara Parker, and RG Cravens. 2016 "The Inclusive Classroom." PS: Political Science $\mathcal{E}$ Politics 49 (3): 574-76.

\title{
Rethinking the Undergraduate Political Science Major
}

\author{
Megan Becker, University of Southern California \\ Jeremy Bowling, University of Nevada, Las Vegas \\ Elsa Dias, Pikes Peak Community College \\ Donald Gooch, Stephen F. Austin State University \\ John Ishiyama, University of North Texas
}

\section{PURPOSE AND HISTORY}

College students today are more diverse, and they face significant and evolving challenges in a rapidly changing global economy. The ever changing political landscape requires flexibility by academics to continue to challenge the political science curriculum in order to better serve students in the 21st century. It is thus imperative that political science as a discipline both considers what we want our students to learn and how we can help them realize their potential in the classroom and beyond. Discerning how political science is different from other social sciences is important for the redesign of the major as well as setting new expectations for students, faculty, and practitioners. To facilitate the discussion of a major redesign, the APSA special projects fund provided backing for a small threeday conference in the spring of 2019. The conference working group was convened by John Ishiyama at the University of North Texas to discuss updating the 1991 Wahlke report. Of the 12 recommendations of the Wahlke report, the group prudently debated the following recommendations:

- A common introductory course, such as an introduction to politics or an introduction to American government taught in the comparative context.

- A scope and methods course that would expose students to normative and empirical methods of inquiry.

- A capstone experience in the senior year, giving students the opportunity to integrate and synthesize prior learning.

- An approach to include diversity, broadly defined, across the political science curriculum (Wahlke 1991).

\section{AT THE 2020 APSA TLC}

The Rethinking the Undergraduate Political Science Major track at the 2020 APSA Teaching and Learning Conference brought together students, administrators, and faculty from all ranks, representing a variety of institutional contexts, in order to define a vision for the future of the political science major. The goal was to generate ideas regarding the curricula that we might use to fulfill a set of aspirational disciplinary learning outcomes and skills that reflect market needs post graduation. As the working group deliberated over learning outcomes for the undergraduate major and a curriculum that meets the 21st century needs of students, the group was cognizant of the challenges that exist today in higher education, the job market, and with students' lives in general. A unifying theme of the discussions was that the trans- fer of skills from faculty to students, or business as usual, must be challenged, because students have a plurality of identities and interests that must be both recognized and fostered in a more dynamic educational setting. The participants worked to provide the entire discipline with a plan that accommodates institutional differences and that is sensitive to diverse curriculum needs.

Ultimately, the 2020 APSA TLC working group accepted the Wahlke Report's challenge to "equip [students] intellectually to comprehend and deal with their political world after graduation, in ways appropriate to their individual inclinations, be it 'merely' as intelligent citizens, as journalists, as active participants in business or in electoral politics, as candidates for office, or even as academic political scientists... it should aim at political education in depth."

The track began with a global discussion of the challenges facing political science students today, the purpose of a political science degree, and the discipline's essential components. Prior to the conference, the track lead, John Ishiyama, sent track participants the conference program for the spring 2019 working group meetings, a draft summary report from the previous conference working groups, the 1991 Wahlke Report, and Marineau (2020). He 
asked the participants to read the materials prior to the APSA TLC conference. When the track met on the first day of the conference, Ishiyama laid out the overall purpose of the working group and the general organizational structure for the weekend. The working group discussed themes in major design, the Wahlke Report, and Marineau (2020).

The first task for the working group was reshaping the vision statement for the political science major that will serve students in the 21st century. Looking for disciplinary common ground, the working group proposed a vision of what the political science major ought to look like as we move forward into the 21st century. An important part of this vision is to establish the strengths of political science and how it differs from other social sciences. Political scientists need to have common language to communicate to students what it means to have a degree in political science. One key element of the meeting was to establish what tangible benefits a political science degree has to offer to students. Another key issue was how to communicate to students a sense of curiosity about being engaged in political life and the lifelong benefits that a political science degree offers.

Once the vision statement was formulated and consensus on it was achieved, the track broke out into groups of about 5-6 members, with consideration for institutional diversity. Group work would proceed on the second day. Each group was tasked with a dual charge to guide their work: first, to identify core political science knowledge themes for the discipline, i.e., what the core of a political science major's knowledge base should consist of; and second, to identify a core set of skills the discipline can provide majors, i.e., what majors should know how to do once they have completed their degree. As the groups discussed various aspects of designing the major, the participants remained cognizant of diverse student body issues, job market skills, institutional diversity, and curricular structures that could be implemented at any higher education institution in devising the learning outcomes while also maintaining disciplinary uniqueness, aspirations of the discipline and its core values. One key theme was to recommend a major design that would focus on the development of core skills students can use in a variety of professions.

Once the group work was completed and each group had developed preliminary lists, then the knowledge and skill themes were aggregated and discussed by the whole track. At the lunch break, a small working group developed learning outcomes based on the aggregated knowledge and skills. When the track reconvened, the learning outcomes were debated, revised, and voted on. Touchstones for rethinking the major were addressed to the satisfaction of all those who participated. A key focus was on expanding the scope of the political science major beyond the confines envisioned in the Wahlke report. There was broad agreement that the Wahlke report had deemphasized leadership, civic engagement and competency, and workplace skills in its report, and that this was untenable for a political science major in the 21st century. The working group drew from an extensive literature on civic education, leadership, and the skills necessary for employment in order to craft learning outcomes. The article published by Josiah Franklin Marineau, where the author presents three models of what political science students do with a political science degree, namely researcher, activist, and leader, was an integral part of the Friday afternoon discussion. This discussion helped the working group hone in on the skills that should be at the forefront of disciplinary learning outcomes in the major. While the pathways to employment political science majors may take are too numerous and varied to fully identify, the working group addressed the core knowledge, skills and experiences that the major can provide that will transfer to their lives and into their working environment.

On the last day of the conference, the track convened into small groups to discuss and develop recommendations for curricula. The participants kept in mind the variety of undergraduate institutions when discussing recommendations for suggested curriculum. Participants discussed that the final recommendation to the discipline include suggested curriculum based on institutional type. In the end, the track was productive. While there were disagreements over the language of learning outcomes and curriculum requirements, the track moderator ensured that everyone had a voice and that no one dominated discussion, and there was broadly expressed satisfaction with the progress made in the working group towards a report reimagining the political science major.

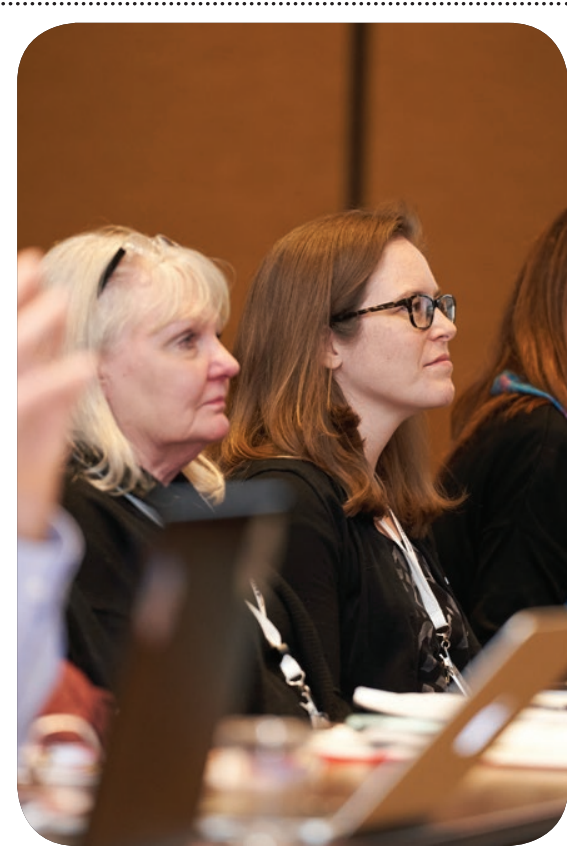

After convening the track in Albuquerque, many of the APSA TLC track participants will continue working through the spring and summer of 2020. Based on the work completed during the track, participants will be broken into groups to help finalize a draft report. The report will include a vision for the major, content and skills-based learning outcomes, example curricula, and evaluation strategies. One of our highest priorities is to encourage participation in the construction of the draft from 2-year undergraduate institutions, 4-year liberal arts institutions, 4-year primarily undergraduate institutions, MA/MS institutions, and $\mathrm{PhD}$ institutions. This will help make sure that a diversity of institutions and ideas are represented and that the recommended learning outcomes and skills serve as a pragmatic set of doable and institutionally-sensitive proposals. The final draft will be presented at the 2020 APSA meeting in San Francisco. Interested faculty, particularly those who are tasked with working on their department's curriculum, are encouraged to attend a special panel at the annual meeting that will provide an overview and discussion of the report.

\section{R E F E R E N C E S}

Wahlke, John C. 1991. "Liberal Learning and the Political Science Major: A Report to the Profession." PS: Political Science \& Politics 24 (1): $48-60$

Marineau, Josiah Franklin. 2020. "What is the Point of a Political Science Degree?" Journal of Political Science Education 16 (1): 101-107. 


\section{Simulations and Games I: Strategy, Game Design, and Constitutions \& Treaties}

\author{
Michael Toje, Louisiana State University \\ Kristina Flores Victor, California State University, Sacramento \\ Katherine Trubee, University of Tennessee, Knoxville
}

The overarching concept in this year's Simulation and Games Track I was to explore ways to encourage students to think creatively about political problems and solutions. The simulations presented in this track help to convey complex ideas and theories to undergraduate and graduate students. The presentations also demonstrated the process for how simulations and game play enable students to learn and apply complex concepts and theories. Presenters showed many different methods for developing and expanding the role of simulations in their classrooms with the end goal of engaging students as citizens; echoing the sentiment expressed in the keynote address for civic engagement to be explored in the classroom. Presenters coming from diverse institutions, from private and public four-year degree institutions, community colleges, and even graduate programs, gathered to relate their experiences with developing and implementing games and simulations to deepen learning in the classroom. As learning management systems (LMS), educational mobile apps, and e-textbooks become increasingly ubiquitous in academic settings, there is a growing awareness and appreciation for in-class games and simulations as additional and useful pedagogical tools. There are three main themes that emerged over the course of the Simulation and Games Track I: reconsidering the classroom, politics and games as rulesets, and civic engagement simulations.

\section{RECONSIDERING THE CLASSROOM}

The first major theme for the Simulation and Games Track I was how to recontextualize course material through simulations. The principal use of simulations, of course, is to demonstrate the operations of a model of some real-world phenomenon. The first presenter for this year, Chad Raymond, discussed his usage of simulations as a teaching device for students. His presentation, "Teaching with Design Thinking," is a primer on game design-more importantly, how students design their own games to understand concepts and ideas of politi- cal science. Raymond's entire process is something he calls "SCAMPER," but for the purpose of the panel he focused on three essential elements taken from engineering for teaching students how to teach themselves: problem, ideation, and experimentation. The benefit of such an approach is that the students must have a sufficient understanding of the course content in the first place in order to design an appropriate game to model it. Thus, the simulation is secondary: by thinking of how to write a game with certain rules and incentives, students must look at the particulars of that theory.

In a similar vein, Xiaoye She gave her presentation on the setting and the staging she employs in her classrooms to engage students with her simulation. The simulation recreates the ASEAN summits, which allows her students to learn about concepts important to international studies such as: multilateralism, sovereignty, regional hegemony, and balancing. She shared with the panel photos of her students recreating the ceremonial ASEAN linked handshake and selected speeches from her students given during the simulation alongside real speeches from the actual member-states. Finally, She concluded her presentation stressing the importance of providing an appropriate space to emulate a simulation's real-world subject. The goal of a simulation is to get students to experience first-hand what goes into policy and decisionmaking by these heads of state. Forming the linked handshake at the beginning of every round of simulation signaled to students that they were now to embody their roles as delegates of the ASEAN member states, which imparts a layer of verisimilitude to the simulation.

Lastly, Andrea Kay Kent's presentation proposed allowing students to design their own games as the final project for the course. Much like Raymond's approach to using simulations in the classroom, Kent's students are able to demonstrate they understand their chosen topic well when they can devise a game that models how the concept works in the real world.
Kent makes use of simulations not to recreate a scientific model of some aspect of political behavior, but as a method to facilitate students' creativity. The goal of designing a game as a final project is to direct students towards free-form creativity over a more causal, problem-solving orientation. The three stages to foster an entrepreneurial mindset are creation and innovation, experimentation and adaptation, and application and explanation. The first stage, creation and innovation, teaches students self-discovery, as they recognize that no one right answer exists, and so they must play around with various game designs to determine what best serves their goals. The students have no explicit instructions of how to design their games, instead they develop self-sufficiency along the way. Experimentation and adaptation, the second stage, teaches students failure is a constructive, and not destructive process. Failure shows one what does not work, and forces one to examine our presuppositions critically in order to work towards a desired end. Finally, the third stage, application and explanation, teaches the so-called "soft skills" of conveying process and purpose. These skills demonstrate an understanding of critical evaluation itself, which is a trait that prepares students for their careers after college, and can carry over to any career field, not just political science. Kent concluded in the presentation that the semester ends on a game day where students play one another's games in a round-robin style tournament and assess each game's merits to one another according to innovation, clarity of purpose, and ease of play.

\section{POLITICS AND GAMES AS RULESETS}

The second theme of the Simulation and Games Track I is that of politics and games as rulesets. The presentation by Keith Hollinger discussed how to use simulations to learn about the formal and informal rules that structure politics. The specific concept around which Hollinger bases the simulation he uses in his classroom is that of conflict analysis and resolu- 
tion. The students divide into groups that each control one country in the world. The students have the simple goal of reducing conflict, but the mechanisms they choose are up to themselves to devise. The simulation encourages students to think of how to change the status quo of mutual distrust to one of mutual cooperation, or at the very least mutual tolerance, by changing the incentives for how each state pursues its goals. Hollinger uses his simulation to teach students how to "think on the margins" and create their own systems for mitigating interstate violence. The rules evolve as the simulation proceeds, showing students that norms, laws, structures, and institutions are emergent rules created through trial and error. Students can then make use of this lesson from international politics to carry over to other aspects of their education in learning how to overcome disagreement for some collective benefit.

\section{SIMULATIONS AND CIVICS}

The third theme is the use of classroom simulations to encourage students to become more civically engaged. These civic engagement-based simulations reflect the theme of the 2020 TLC keynote address, and the importance of teaching and promoting civic responsibility and political participation. Important elements of political participation and civic engagement are the abilities to articulate one's preferred policy outcomes and to learn how to organize like-minded citizens into coalitions to achieve these goals.

Kristina Flores Victor presented on her California politics direct democracy simulation, which allows students to actively participate in a series of simulated elections in the classroom. The main goal of the simulation is understanding the important influence of social group identity at the ballot box. While the simulation is based on California's direct democracy system, Victor's simulation uses a minimal group experimental set-up. As a result, the driving motivation for vote choice for each election is self-interest based on group characteristics given to each student at the beginning of the simulation. The group characteristics given to the minimal groups are representative of the different minority groups in California. The simulation allows students to participate in coalition building, resource distribution, intra-group leadership, and political spending and strategizing.

Christina Barsky presented on two different public budgeting simulations (local and federal) used in a graduate MPA program. The first simulation was an in-depth budgeting simulation which takes place in a fictional town called Knievel-ville, where students were assigned roles and asked to make decisions about how public monies are spent in this fictional town. The second simulation budgeting tool presented by Barsky is called Fiscal Ship, it was developed by the Brookings Institution and can be played for free online. Fiscal Ship can be played by a wide range of ages and abilities, playing the game demonstrates to students the competition and tradeoffs between different priorities in making the federal budget. Fiscal Ship was described as a shorter game that can be played repeatedly at the beginning of the module and again at the end as students master the content.
Greg M. Shaw presented the third simulation in this group, a well-developed simulation designed to teach students about distributive justice. This simulation is called "Shipwrecked with John Rawls" and Shaw uses the simulation at the start of the semester and not only a teaching tool but an icebreaker for the students. Shaw gives his students biographical information about the list of individuals trapped on the island with a shipwrecked boat. Students do not know which of the virtuous or wicked characters belong to them. Without knowing their role in the game, students must allocate resources and spare work hours while working to the common goal of escaping the island they are stranded on. After hours and resources have been distributed, and fates have been determined, students learn of their true identity in the simulation.

In each of these three simulations students are put in the position to experience political decisionmaking, political outcomes, and cooperation among group members for a common or collective good.

\section{CONCLUSION}

In conclusion, the lessons learned from this year's Simulation and Games Track I presentations is that simulations and games serve many purposes, and they can take many forms in the classroom. Games and simulations are able to: (1) foster a deeper understanding of complex concepts and material; (2) allow students to roleplay or imagine life through another perspective; (3) develop relationships between students; (4) innovate in the classroom; and (5) be used to creatively assess learning outcomes.
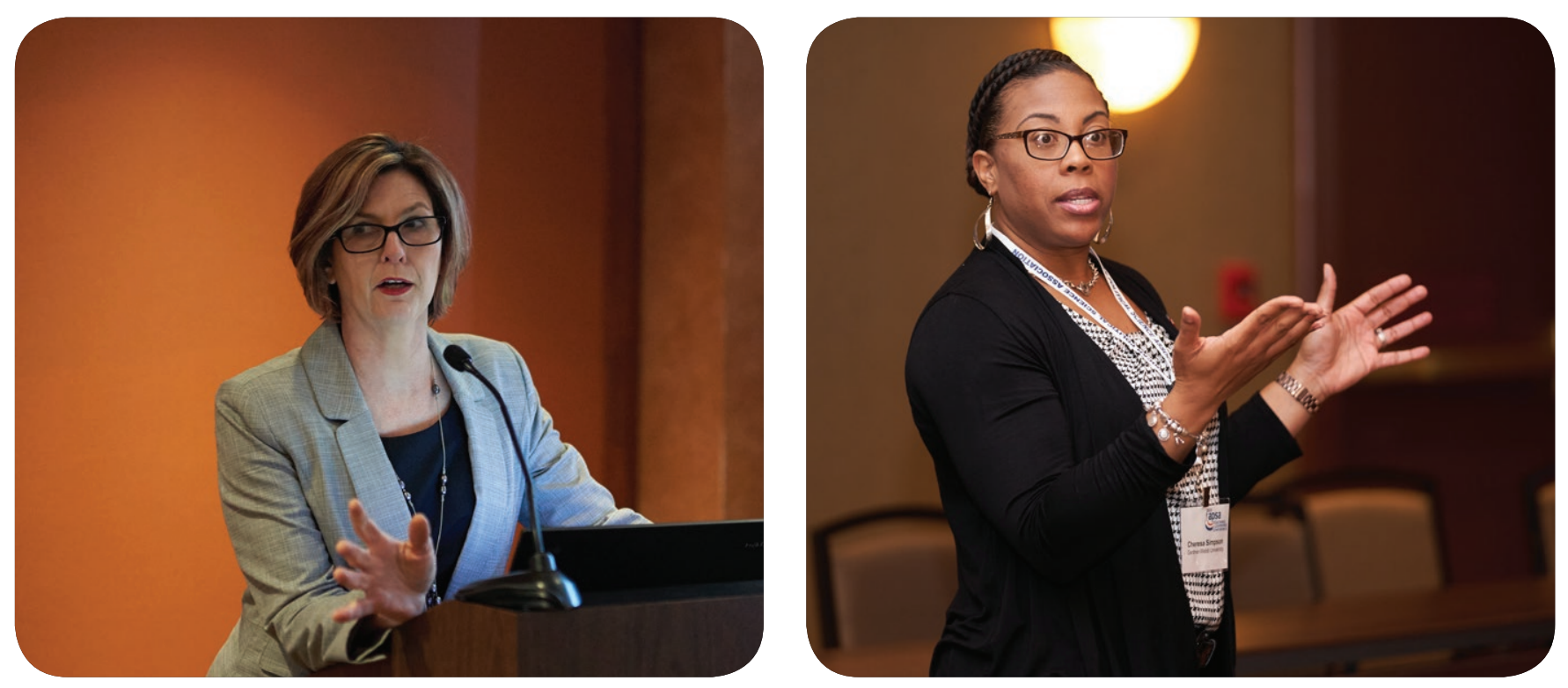


\title{
Simulations and Games II: Evidence, Innovation, and Institutions
}

\author{
Khalil (Haji) Dokhanchi, University of Wisconsin, Superior
}

T he Simulations \& Games II: Evidence, Innovation, and Institutions track provided a good array of examples for the participants in terms of effective and innovative teaching methods in an era of active learning and student engagement. As Edward Kammerer and Brenden Higashi's "American Politics Simulations: A Gap in the Literature?" pointed out, research on simulations are not only published and used in the area of world politics, but in all the subfields of political science. Indeed, there were nearly two days of examples of simulations from nearly every subfield except methodology.

Two topics permeated through all the presentations. First, simulations are constructed for pedagogical purposes. The activities are intentionally created to align with the teaching purposes of the courses. Almost three quarters of the meetings focused on the variety of innovative ways to teach various concepts and ideas using simulations. The presentations varied from Victor Asal's opening presentation on "Playing Poker with Key Thinkers of International Relations" and his two-hour workshop on using simulations to teach about political violence, to a variety of presentations that were focused on particular issues and concepts. Adam Howe, for instance, had an excellent simulation on post-election coalition building in a parliamentary democracy. By using Great Britain as an example, he provided his students with the information about various political parties and their relative electoral success. The students then had to negotiate with each other to form a coalition government. Alex Smith and Stephen Phillips used a budget simulation to teach students about Williams Riker's heresthetical tactics of agenda setting, strategic voting, and dimension manipulations. Khalil Dokhanchi's simulation provided students with a real-life journey of refugees from Syria to Germany and incorporated various international law components so participants would know the difference between refugees and migrants as well as the protections for each group.

The second topic revolved around

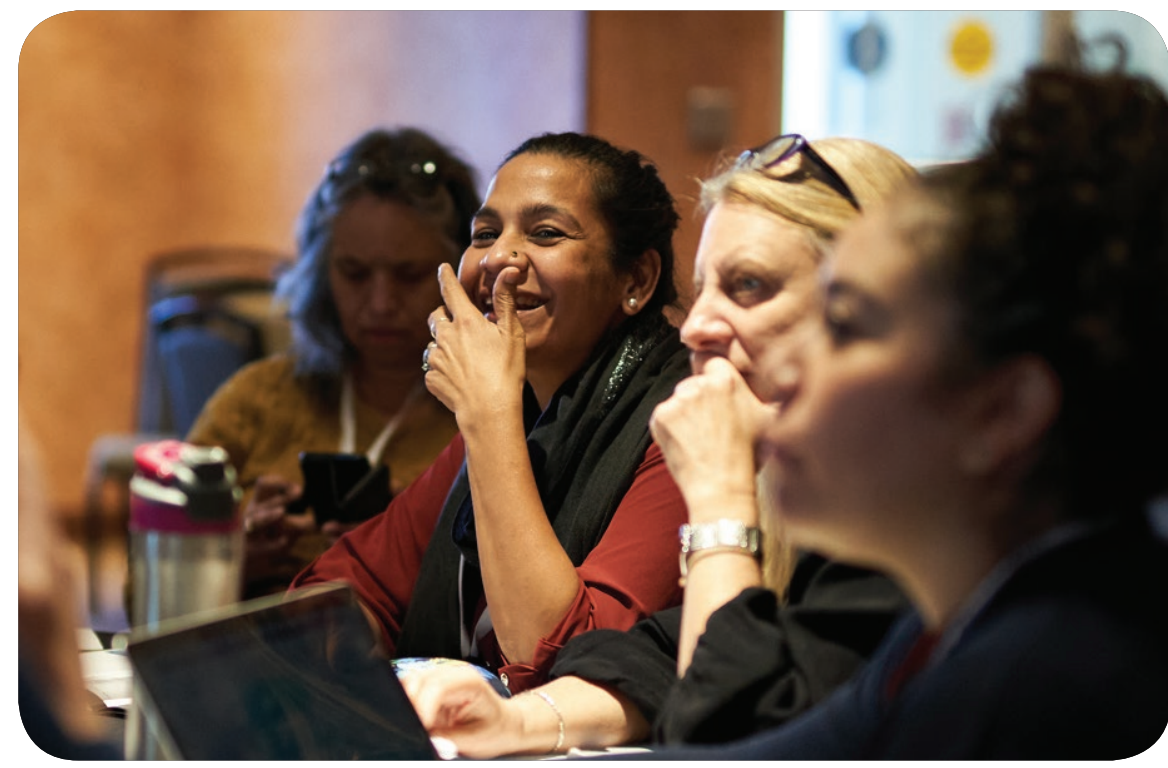

another trend in education today: assessment. How well does what we do work and how do we justify such activities? There is increasing pressure across higher education institutions at all levels to illustrate that their teaching methods work. Therefore, every study that provides evidence (more than anecdotal evidence) is particularly welcome. The types of evidence (namely self-reported vs. regression analysis) and the expected outcomes become important. All of the studies that focused on assessment found that simulations were effective teaching techniques. Studies by Dokhanchi, Howe, Smith and Phillips, Kelly SiegelStechler and Gretchen Knudson Gee, and Margaret Emily Edwards, Philip Hultquist and Yann Kerevel all provided evidence of teaching effectiveness. The former studies were merely self-reported while the latter studies utilized more "hard-core" regression analysis. While the evidence on learning and teaching effectiveness was conclusive, the more "rigorous" studies failed to show that simulations resulted in increased civic attitudes among students or higher-order thinking such as critical thinking abilities among students. Perhaps, as Hultquist argued, it is too much to expect a mere class activity such as a simulation to have such an overarching effect. The outcomes desired here are linked often to the assess- ment of overall undergraduate political science programs, and it is unreasonable to assume that one activity could achieve such outcomes. Perhaps more discussions should focus on how to confirm the value of simulations outside of self-reporting.

Both active learning and teaching assessment trends lead us to celebrate endeavors that provide evidence of success. While the celebration of good scholarly work is always valued, it is also important to note that many of these successes are based on years of trials and failures. These presentations illustrate how committed graduate students and faculty worked through many attempts to become successful. It is hoped that the search for teaching effectiveness does not stifle teaching creativity. In the post-pandemic era, there will be a greater need for creativity than anytime in the past 50 years. Knowledgeable and educated people will be necessary to develop creative political solutions to such overwhelming events. 


\title{
Teaching Research, Writing, and Information Literacy
}

\author{
William O'Brochta, Washington University in St. Louis \\ Julia Marin Hellwege, University of South Dakota
}

S ince the publication of the Wahlke report in 1991, political science departments have created research methods and senior capstone courses as ways to introduce students to the political science research process. However, the traditional format of these courses has not been able to provide an immersive and cohesive research experience as there are simply too few opportunities to practice and apply newly learned skills to contexts relevant to students.

The 2020 TLC Teaching Research, Writing, and Information Literacy track emphasized ways to turn those courses and skills into experiential learning opportunities that expand research methods beyond statistics and consider integrating both the consumption and production of research methods skills throughout departmental course offerings. This approach offers students in introductory courses the ability to gain social science research skills, develops a scaffold upon which research skills can be built iteratively, and provides students with the opportunity to practice these skills at varying levels throughout their coursework.

Track panelists agreed that a holistic view of what, when, and how research methods are taught will more effectively prepare students for both capstone writing assignments and the type of analytical thinking increasingly required on the job market. Toward this end, track panelists presented strategies for expanding the scope of current research methods and writing courses and approaches to integrating related skills across the curriculum. In surveying the existing literature, Mitchell Brown, Bob Smith, and Cameron Theis noted there is a relative lack of pedagogical literature and tangible tools available to instructors to expand the scope of research methods and to integrate these skills throughout the discipline. Our track answered this call through a set of innovative and diverse interventions from across different types of institutions.

\section{EXPANDING THE SCOPE OF THE RESEARCH METHODS COURSE}

When a research methods course focuses exclusively on statistical content, students miss the opportunity to understand how research methods relate to the broader research and writing process. This exacerbates students' struggle to understand how statistical concepts are relevant to answering political questions and de-emphasizes the critical role of research design and writing in political science. Within the traditional research methods course, track panelists presented two innovative approaches to increase the scope, relevance, and cohesiveness of the traditional research methods syllabus.

Both Anne Pitsch Santiago and Renato Corbetta explained how research methods courses can be structured to bring together research design, qualitative and quantitative analysis skills, and an emphasis on topical political issues. Pitsch Santiago emphasized the critical role a research methods course can provide in linking research design and writing skills with qualitative and quantitative methods. The opportunity to tie together strategies for developing a well-grounded and articulated theoretical argument with the methodological skills to analyze said argument provides a powerful way for students to learn by doing. Corbetta described being forced to re-think teaching research methods when teaching it for the first time in an online classroom and agreed that synthesizing theory and methods is crucial, even given this much different course format.

Both presentations represented approaches to teaching research methods in different contexts, and track panelists agreed that the common thread of increasing the relevance and accessibility of research methods courses will help improve student learning outcomes, retention in the major, and more effectively develop critical thinking skills.

\section{INTEGRATING RESEARCH, WRITING, AND INFORMATION LITERACY ACROSS THE CURRICULUM}

Expanding the scope of the research methods course is, however, insufficient to fully prepare students for conducting research in their future careers. Repetition, practice, and scaffolding research design and methods skills throughout the curriculum are key methods to increase student confidence and ability to perform these tasks.

Track panelists applied these ideas to a diverse set of research, writing, and information literacy topics in a wide variety of classroom settings. Our main takeaway was that introducing research design and methods skills can and should occur in every course in the discipline, and that there are a number of successful models by which to do so. As we emphasize later, though the investment of single instructors is crucial for this approach to work, additional departmental and discipline support is needed for research design and methods skills to be truly integrated into the fabric of all courses, regardless of instructor or institution.

\section{Building Foundations in Introductory Courses}

Introductory courses often provide students with their first exposure to the discipline and are often non-majors' only way to learn about the social science research process. Track panelists paid special attention to integrating research design and methods skills into introductory courses. Approaches varied based on substantive course content and the type of students likely to enroll, as well as the instructor's vision for how the skills taught in an introductory course could be built upon in future disciplinary coursework. Interventions occurred in introductory American politics, comparative politics, international relations, public administration, state politics, and disciplinary survey courses. The size of the intervention in these courses ranged from low stakes exercises to new activities to major structural reform. 
Given that students are often hesitant to tackle data literacy, low stakes classroom and homework exercises are an excellent way to introduce these concepts or to help students draw theoretical links between course topics. Karen McCurdy developed a series of data literacy and analysis exercises to complement her textbook for Introduction to American Politics. These exercises are meant to help students consume and interpret data in preparation for applying data literacy skills in future courses. Similarly, Brady Collins and Robert E. Nyenhuis introduced concept maps as an active learning method to increase students' ability to synthesize course material, a key skill for summarizing literature and developing a theoretical argument. Their experimental intervention showed that making concept mapping a regular in-class activity improved student synthesis and retention compared to a control course without concept mapping.

Building on the idea of lower stakes assignments, but in a graduate level introductory course, Christopher K. Butler's presentation on strategies for "gamifying" research methods concepts using online quizzes stressed the importance of making both course content and teaching methods timely and relevant to students. Students of all skill levels appreciated the opportunity to use the online quiz as a learning tool, repeating it multiple times to practice difficult to understand skills and to figure out how and why they made mistakes.

Beyond frequent low stakes exercises, track panelists also developed summative assessments to evaluate student data literacy and understanding of political science research. These assessments were coupled with small changes to course structure that enabled students to engage more deeply with research design and methods skills. Such interventions look different for different types of students. For their introductory courses in a masters in International Policy Management program, Tavishi Bhasin and Charity Butcher designed repeated infographic and policy memo assignments that emphasized the practical applications of political science research. Both interventions could be implemented just once during the semester, but panelists repeated these assignments multiple times in order to provide students with space to practice research skills within the course. Josue Alejandro Franco presented an excellent formula for teaching community college students to read a journal article through guided and repeated practice.

Adding several repeated research design or methods assignments throughout a course is an effective tool for teaching these skills without radically changing the course structure. However, a thoughtfully re-designed introductory course that makes research design and methods skills core student learning outcomes builds a stronger research foundation that will help students in future courses. Andrew Michael Wender and Valerie D'Erman particularly emphasized the important role understanding broad theoretical debates in the discipline has for structuring students' knowledge of what political science research is and the types of questions research methods can help answer. William O'Brochta showed evidence that students in an introductory course designed to teach the research article writing process greatly improved research design, methods, and writing skills to a level comparable to more experienced senior capstone students.

\section{Applying Foundational Knowledge in Upper-Level Courses}

Not all research design and methods interventions work in introductory courses. In particular, introductory courses may be more effective at providing an overview of many of the techniques involved in the research article writing process, whereas upper-level substantive courses provide a place to more deeply investigate specific research, writing, and information literacy skills. Nina Rathbun and Iva Bozovic's data literacy experiments showed just this, finding that a simple data analysis paper in an introductory course did not improve data literacy, but that students in an upper-level course asked to more intentionally reflect on common problems in data analysis did improve data literacy.

By introducing strong foundational research, writing, and information literacy skills in introductory courses and providing repeated opportunities to develop and practices these skills in substantive courses, students entering a senior capstone course can carefully focus on polishing their research and writing skills instead of having to learn them from scratch. Colin Brown demonstrated the utility of this scaffolding model by engaging students in intensive peer review in a senior capstone course. Peer review works best when students have already developed research and writing skills, enabling them to offer more careful and substantive comments than if they were learning these skills for the first time. Careful scaffolding can allow for senior capstone experiences to re-focus on improving research skills instead of teaching them for the first time.

\section{Research Methods Outside the Course Context}

Scaffolding research methods skills can also be particularly successful when integrating them into extra-curricular departmental opportunities. Natasha T. Duncan and Nadia E. Brown presented one such model, introducing applied qualitative research methods as part of a one-time fieldwork trip to Washington, DC. Students worked collaboratively to understand research methods concepts while engaging in data collection. As Kelly Bauer showed, these types of experiences can be made into ongoing research laboratories where institutionalizing a student chain-of-command can make it feasible for instructors to supervise out-of-class research article writing teams.

\section{CALL TO ACTION}

Departments need ongoing wholesale discussions about teaching research, writing, and information literacy skills that go beyond the content taught in traditional statistical research methods courses. While our track panelists presented new and exciting ways to expand the research methods course and to integrate research design and methods topics throughout introductory and substantive courses, this effort cannot be successful if championed by only a few faculty members. Applied and experiential learning about the political science research writing process requires departmental learning outcomes emphasizing these skills, assessment throughout coursework, and confidence that students can produce high-quality political science research.

Resources are available to assist in this mission. First, university subject librarians and writing center instructors can be invaluable assets when carefully integrated into curriculum design. Second, departments can gain inspiration from published work on teaching research, writing, and information literacy concepts and should encourage instructors to engage in and publish scholarship on this topic. Finally, APSA can encourage departmental progress by making its broader membership aware of research design and methods innovations that go beyond requiring a quantitative research methods and a senior capstone course. Though the exis- 
tence of such courses does provide a basic structure upon which a holistic approach to teaching political science research skills can be built, few departments have integrated and synthesized research methods into the curriculum in a way that provides a truly significant learning experience for students. Research, writing, and information literacy skills are crucially important for fostering critical thinking and preparing students for the workforce as well as for those students interesting in pursuing grad- uate studies. We as a discipline and instructors can do more to ensure that students are able to benefit from a full complement of these skills.

\title{
The Virtual and Technology Enhanced Classroom
}

\author{
John L. Phillips, Austin Peay State University
}

W hen the Virtual and Technology Enhanced Classroom track met in early February, none of the participants knew that by the middle of the following month nearly all of their colleagues would be teaching online. The spread of the COVID-19 virus challenges the resilience of faculty by forcing many of them to adopt of a medium of instruction that continues to challenge even its most ardent supporters. This track summary is organized around a series of trade-offs that arise as a result of the technologies now available to instructors both inside the classroom and out.

\section{STUDENT SATISFACTION \& STUDENT GROWTH}

The tension between keeping students happy with their online experience and stimulating learning outcomes like selfreliance, critical thinking, and active learning is not unique to the virtual classroom, but it manifests itself in different ways as technologies change and norms about their use evolve.

Students expect to be taught, but what matters is that they learn. This is one of tensions highlighted by a paper presented by Pablo Biderbost on flipping the classroom in a Spanish university. Flipping the classroom is a technique that reverses the usual instructional pattern where students learn in class and do exercises at home. In the flipped classroom, students are expected to learn through readings and online videos at home and come to class to discuss and apply what they have learned. Interviews and surveys of learners, however, reveal that students expect the professor (as a subject matter expert) to teach them information, not facilitate activities. These norms about the appropriate roles of faculty in the classroom can clash with best practices for any

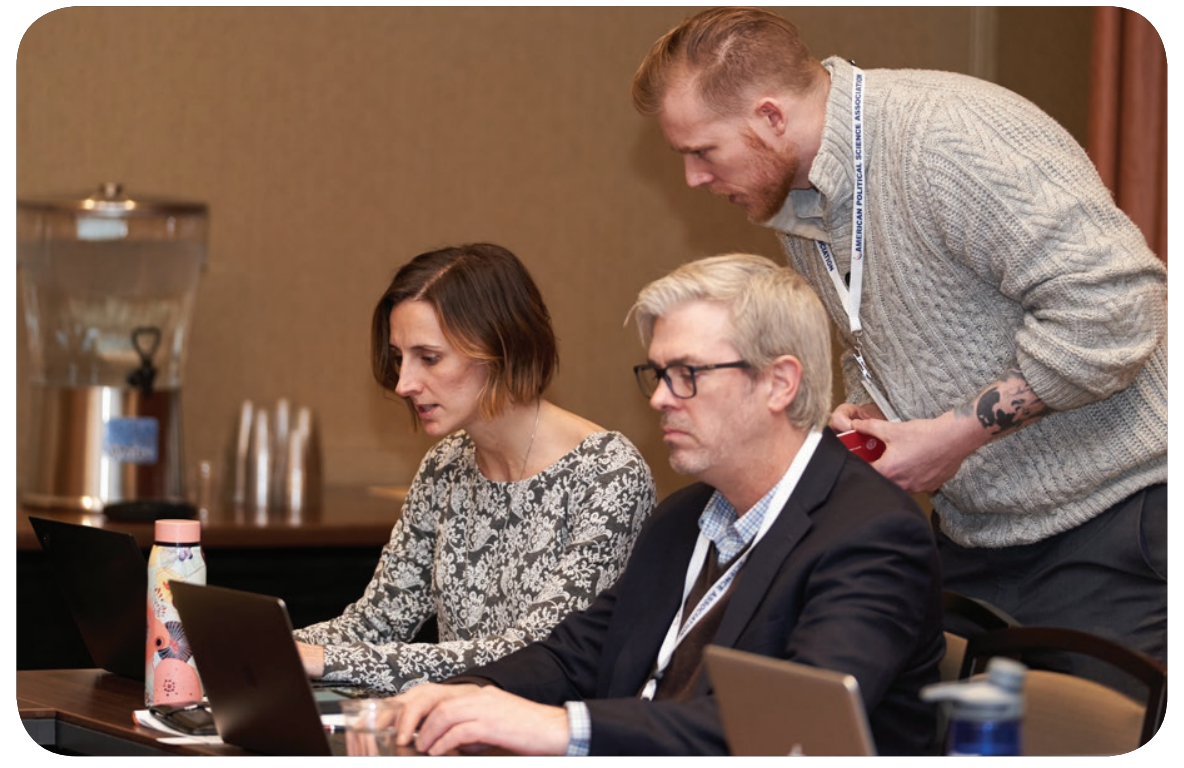

given subject matter. This tension highlights a need to involve students in conversations about pedagogy in higher education as the role of the instructor changes. Involving the students in these conversations can help manage expectations about the role of faculty in the learning process.

Online students value clear instructions, but there is no step-by-step formula that can reliably produce higher order learning. Rebecca Glazier presented findings from a survey of 2,007 students about the best and worst classes online (and on campus) they had ever taken. Among the roughly one third of students who rated an online class as the best class they had taken in college, students rated clearly spelled out assignments and step-by-step instructions among the essential reasons for their ratings. For some learning outcomes, however (creating an amusing political meme, composing an original persuasive essay), there are no formulas that will reliably guide students to the desired results. To be sure, much can be done to clarify the instructions given by online faculty without abandoning the quest for high order thinking and creative skills. Sample "A" work, discussions of sample work that is unsatisfactory, and the use of checklists can all be immensely helpful to students.

Online discussion boards are good for student satisfaction, but perhaps not necessarily for developing critical thinking skills. Asynchronous discussion boards help to create a community of learners. They have been shown to enhance student satisfaction and retention. In principle, they also provide a low stakes avenue for practicing reading, writing, and thinking skills on questions that are analogous to the ones they might be asked to wrestle with in key course assignments. Appearances can be deceiving, however. John Phillips presented some preliminary evidence from a dozen sections of an online political theory course which found that, controlling for standard determinants of critical thinking, no significant differences in critical thinking scores could be observed between sections where 
discussions were used and in courses where discussions were cut in favor of extra essays or other work. Furthermore, in courses where discussions were required, no relationship could be found between the quantity of posts from a student or the number of required topics and critical thinking scores. Despite their advantages when set up properly, if faculty can find other ways to entertain students, discussions boards need not be a component of successful online learning. New faculty teaching online who look upon the prospect of wading through hundreds of student discussion posts with dread can likely find alternative ways of delivering quality learning outcomes.

\section{DEMOCRATIZING ACCESS VS.} ENGAGEMENT \& RETENTION

MOOCs (Massive Open Online Courses) are cheap, but students often drop out. For quite some time, MOOCs have promised to democratize access to higher education around the world through low-cost standardized certification. A single MOOC can admit thousands of students and typically combines short videos, readings, and assessment quizzes. According to research presented by Ana Figueroa on IPSA MOOCs, completion rates are low when the courses are offered for free. They are better when students have to pay (usually to receive certification).

What is missing from the MOOC model is what several other presenters showed as helping online courses retain students: namely active instructor "presence” (Daigle), responsiveness (Glazier), and creating an emotional connection to the course material (Pahre). This raises the question: what good is near universal and costless access if students are not motivated to finish the course? Instructor presence and responsiveness is costly, however, which tends to undermine the traditional MOOC model.

To the problem of low completion rates in MOOCs two possible solutions were offered during the discussion that would not compromise the low-cost model of education but also attempt to introduce some motivation to complete the course. First, based on his own paper investigating the consequences of providing on-location videos for an online section of an environmental politics course, Robert Pahre suggested creating videos for MOOCs specifically aimed at stimulating an emotional connection between the students and the subject matter. This stimulus to intrinsic motivation can be done by presenting real life stories and (if feasible) filming on location where these stories take place. Secondly, John Phillips suggested that rather than having MOOCs be wholly free (or as an additional option to a free MOOC) a course fee could be held in escrow in exchange for course completion (a form of extrinsic motivation).

\section{CLASSROOM RESPONSE TECHNOLOGY \& CIVIC ENGAGEMENT}

A Classroom Response System (CRS) is an application or device (such as a "clicker") that enables students to respond in real time to questions posed by the professor in the classroom. According to two separate papers by Matthew Record and Daniel Mallinson, CRS holds out the promise of improving self-confidence and civic agency (particularly among students from lower socio-economic status environments) by allowing students to respond to professor questions before being called on or before having those views discussed by the class. This can help everyone in the class feel valued (not just those who raise their hands quickly and often in class) and can lead discussion towards points of view that might not otherwise be considered. However, some discussants saw widespread adoption of this technology as potentially coming into tension with the goal of developing active citizenship skills, especially for those who may not feel that their voices are appropriate or welcome in arenas where they have traditionally not been heard. Learning to "speak up" might require becoming comfortable speaking in public even under conditions of uncertainty or even hostility. Removing from the classroom the need to speak or the barriers that make speaking out difficult in the "real world" could have unfortunate sideeffects. Additionally, if only students with something to contribute are called upon to speak out loud after a round of digital responses, the norm "speak only when your voice is solicited" might be unintentionally reinforced.

\section{TECHNOLOGY FOR THE STUDENT \& TECHNOLOGY FOR FACULTY}

Continuing with the theme of trade-offs and tensions, several papers presented yielded the comment that the technologies most convenient for faculty are not always the ones most conducive to student learning (and vice-versa).
For example, in the margins of a discussion on the utility of creating semi-personalized e-mail forms to periodically update online students on their class progress (as a form of "presence"), Rebecca Glazier noted that the times non-traditional online students most need their professors to be available by e-mail or even synchronously are the very same times when professors expect to spend time with their families (nights, weekends).

In their article on the benefits of incorporating technology skills like podcasting, building web sites, and designing infographics into courses, Danvy Le and Antoinette Pole noted that going down this route would require faculty to become more digitally fluent themselves if they wanted to adequately support their students.

Matthew Record's paper noted that CRS in the physical classroom can be helpful to the professor in managing attendance, grading class participation, and checking for reading comprehension. What is an advantage for the faculty, such as knowing who participated how many times and what they said, could be inhibiting and even perceived as threatening by students who would rather be silent than contribute something potentially embarrassing for all to see.

Finally, several of the papers presented exploited data available about students in their university's Learning Management System (LMS). This data is invaluable for understanding how students learn and interact with course content. That being said, an accompanying concern is the contribution of LMSes to normalizing surveillance in society.

\section{OVERLAPPING AGREEMENT}

Though clearly not all good things go together when it comes to technology in academe, some findings emerged from the track that do not seem to be helpfully categorized as trade-offs.

Stephanie Slocum-Schaffer noted that the initial resistance on the part of students to online textbooks observed in the early 2000 s seems to be eroding. Although a minority continues to express a clear preference for physical texts, nowadays there is often little cost in letting students choose which version of a textbook they want to acquire. Only when textbooks come embedded with quizzes and other learning tools does a certain degree of harmonization make sense.

For online student satisfaction, the qual- 
ity of assignments matter. Rebecca Glazier's paper found that whereas students more frequently cited the positive contributions of instructors in the classroom, they cited the engaging nature of assignments more frequently as a principal reason an online class was their favorite.

Reading matters. The percentage of readings attempted and completed by online students is positively associated with a variety of course outcomes includ- ing student satisfaction (Pahre), critical thinking (Phillips), and traditional content mastery (Slocum-Shaffer). Finding ways to get students in online courses to read more is one of the keys to successful online content delivery.

Instructors must be able to adjust their use of technology to the varied student populations they serve. What works at Ohio State may not be best for San Jose State. What works for the North Ameri- can student might not work as well for the student in Spain. Faculty would very much like to know what "best practice" in their field is, but in reality, the answer is all too often "it depends." Much of the scholarship and discussion in this track was devoted to understanding the contexts in which different technologies can be successfully deployed. 